\section{Socioeconomic and environmental determinants of adolescent asthma in urban Latin America: an ecological analysis}

\author{
Determinantes socioeconômicos e ambientais da \\ asma em adolescentes em centros urbanos da \\ América Latina: um estudo ecológico
}

\author{
Determinantes socioeconómicos y ambientales \\ del asma en adolescentes en centros urbanos \\ de América Latina: un estudio ecológico
}

Gisel Lorena Fattore 1,2

Carlos Antonio de Souza Teles Santos 3

Mauricio Lima Barreto ${ }^{2,4}$

\section{Resumo}

A prevalência da asma é alta nas áreas urbanas da América Latina, onde as sociedades exibem altos níveis de desigualdade e diferente grau de desenvolvimento. O objetivo é examinar a relação entre a prevalência de sintomas asmáticos em adolescentes de centros urbanos da América Latina e determinantes socioeconômicos e ambientais medidos no nível ecológico. A prevalência de sintomas asmáticos foi obtida do International Study of Asthma and Allergies in Childhood (ISAAC), fase III. Foi definido um modelo conceitual hierárquico. As variáveis explicativas foram organizadas em três níveis: distal, intermediário, proximal. Ajustaram-se modelos de regressão lineal ponderados pelo tamanho amostral entre prevalência de sintomas asmáticos e variáveis selecionadas. A prevalência da asma foi associada positivamente com índice de Gini, índice de desenvolvimento humano, subministro de água potável, e inversamente com aglomeração e saneamento. Em conclusão, este estudo ecológico fornece evidência da influência da pobreza e da desigualdade social sobre os sintomas asmáticos em adolescentes em um contexto social complexo como o da América Latina.

Asma; Adolescente; Área Urbana 


\section{Introduction}

During the past decades, asthma has emerged as a public health problem in many Latin American countries, especially in children and young people living in urban places. According to the International Study of Asthma and Allergies in Childhood (ISAAC) findings 1, this rising trend began in industrialized countries, and having reached a plateau, the epidemic moved into developing countries, this trend possibly being associated to aspects of recent changes ("westernization") in urban life 2.

Contradicting the so called "hygiene hypothesis", that explain asthma prevalence trend toward increasing as consequence of improved hygiene and reduction in infections, asthma prevalence in children and adolescents is high in Latin American countries, where the lowest socioeconomic groups suffer the greatest burden of disease ${ }^{3}$. On the other hand, different patterns of disease are observed in this region, with the nonatopic phenotype being the most prevalent 4,5 .

A few important risk factors for asthma in adolescents have been identified, most of them related to modern urban life and poverty, like tobacco smoking 6 , obesity 7,8 , exposure to indoor allergens 6,9, low socioeconomic status 10,11 and psychological stress 11 . Adolescents with low socioeconomic status had more severe forms of asthma, greater exposure to chronic stress and poor control over their illness. Additionally, they were more likely to interpret an ambiguous life situation in a threatening manner, suggesting that poverty affects material and psychosocial dimensions of stress in adolescents' lives. This includes both stress exposure as well as stress appraisals, with a consequent impact on asthma symptoms and severity 11 .

However, these well-established individual risk factors cannot explain the large international variation in the asthma prevalence, even within Latin American countries, where the prevalence varies from 4.6 in Mexico city to 30.8 in San Salvador 12. Moreover, global factors like economic development, diet pattern, immunization, poor sanitation and social inequalities have been associated with asthma at the population level 13,14.

We have recently shown a strong association between asthma symptoms and income inequality, living conditions and homicide rates in 6-7 year-old children throughout Latin American urban centers 15 . However, asthma is a complex phenomenon with different manifestations strongly influenced by environmental factors, which might vary significantly with disease stage, and therefore among people of different ages. The ISAAC findings showed a high prevalence of asthma symptoms in adolescents in urban Latin America 1. Moreover, urban centers in lower income countries tended to have higher prevalence of severe asthma, especially in the 13-14 year-old group, where wheezing prevalence was correlated to hospital admission and mortality for asthma, suggesting an important burden of disease in adolescents 16 . Thus, the social determinants of asthma may interact in different ways for this specific age group.

Latin American countries show high levels of inequality, which is observed not only in income distribution, but also in other indicators such as access to infrastructure and basic services, education and health care, reflecting different levels of development, urbanization and lifestyles 17 . Environmental and social disadvantages may explain the large variation in asthma symptom prevalence observed in this region. Hence, this study aims to investigate the relationship between socioeconomic and environmental determinants and the prevalence of asthma symptoms in adolescents aged 13-14 years living in Latin American urban centers according to a predefined hierarchical conceptual framework.

\section{Methods}

\section{Study area and design}

An ecological analysis was conducted. The units of analysis were those urban centers from Latin America that had surveys for asthma symptoms in the period 2000-2003 as part of the ISAAC phase III. ISAAC is a multicenter cross-sectional study of school children in defined geographical areas and was developed to investigate the time trend of asthma and allergies worldwide. Of the two age groups targeted in ISAAC surveys, 6-7 year olds (children) and 13-14 year olds (adolescents), the latter was chosen for the present analysis. Adolescents from 48 Latin America urban centers who self-completed the ISAAC questionnaire were included in the analysis. Two centers were excluded because of the large amount of missing data for exposure variables (San Salvador and Caracas).

\section{Study variables and data source}

Asthma was defined as a positive response to: Have you had wheezing or whistling in the chest in the last 12 months? The asthma prevalence was defined as the number of adolescents with wheezing or whistling in the past 12 months by the total of adolescent participants for each urban center 12 . 
A group of selected variables was selected according to the understanding and availability of asthma social and environmental determinants. Then a hierarchical framework was built considering the complex dynamic of the disease and the potential interaction between different levels of determination (Figure 1).

Variables in the theoretical framework were organized in three levels. At the distal level, the following socioeconomic variables were included: the Gini index (measure of statistical dispersion, used as a measure of income distribution inequality; it varies from 0 to 1 - value meaning prefect equality and 1 meaning perfect inequality) and the Human Development Index (HDI) (composite statistics of life expectancy, education level and gross national income per capita). When the Gini index was unavailable for an urban center, the measured value for the country where the center is located was used instead. The environmental variables were placed in the intermediate level: water supply (percentage of households with a connection to piped water system), sanitation (percentage of households connected to a sewage system or septic tank) and crowding (average inhabitants per household). Health related variables were located in the proximate level and included: homicide mortality rate (number of homicide deaths as classified by the 10th version of the International Classification of Diseases - ICD-10 - in the entire population per 100,000), which was used as a proxy measure for the degree of collective psychosocial stress 18; and the variation in infant mortality rates (IMR) between 1990-2000 using the following formula: IMR variation $(2000,1990)=$ 100*[(IMR 1990 - IMR 2000)/IMR 1990], which was selected because it would represent both the living and the healthcare conditions across the populationineachurbancenterduringtheperiod. In addition, considering that climate conditions may trigger childhood asthma attacks 19, with children being susceptible to thermal stress 20 , the mean annual temperature for the ISAAC survey year was collected and included on the proximate level.

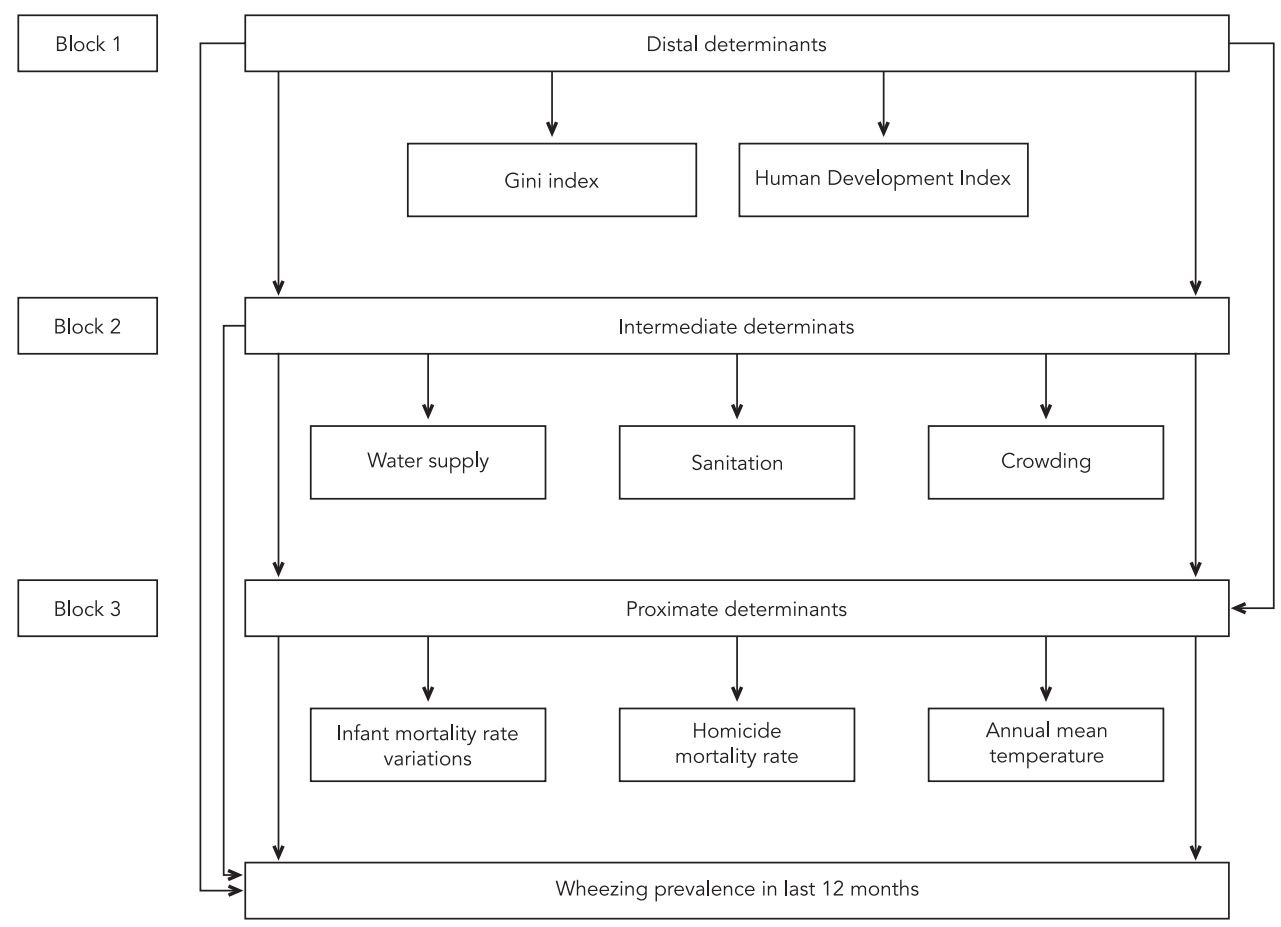


Data were extracted from the Human Development Report (Programa de las Naciones Unidas para el Desarrollo. http://www.undp.org/undp. es/home.html, accessed on Oct/2010), international organizations (Peru: Fondo de Población de Naciones Unidas. http://www.unfpa.org.pe, accessed on Jan/2010. Ecuador: Biblioteca Virtual de las Naciones Unidas en Ecuador. http:// www.un.org.ec, accessed on Jan/2010), national census databases (Brasil: Instituto Brasileiro de Geografia e Estatistica. http://www.ibge.gov.br, accessed on Oct/2010. Cuba: Oficina Nacional de Estadísticas. http://www.one.cu, accessed on Mar/2010. Mexico: Instituto Nacional de Estadística y Geografía. http://www.inegi.org. $\mathrm{mx}$, accessed on May/2010. Uruguay: Instituto Nacional de Estadísticas. http://www.ine.gub. uy, accessed on Jun/2010), and National Ministries (Uruguay: Ministerio de Desarrollo Social. Observatorio social de programas e indicadores. http://observatoriosocial.mides.gub.uy, accessed on May/2010. Bolivia: Ministerio de Salud y Previsión Social. Situación de salud: indicadores básicos 2000. http://saludpublica.bvsp.org. bo, accessed on Aug/2009. Brasil: Instituto de Pesquisa Econômica Aplicada. Ipeadata. http:// www.ipeadata.gov.br, accessed on Oct/2010).

\section{Statistical analysis}

The degree of association between asthma symptom prevalence and the selected variables was measured by the correlation coefficient. To visualize the slope of the relationship between asthma prevalence and independent variables we performed a lowess adjustment.

We used the logarithmic transformation to correct the nonlinearity of homicide mortality rates and we turned the average inhabitants per household into a categorical variable from de median value.

In the bivariate and multivariate analyses we carried out simple and multiple linear regression models with a robust estimate of variance to correct the cluster effect (country) observed between the units of analysis and employed an analytical weight to correct for heteroscedasticity and to compute a linear regression on covariates.

The analytical weight is based on the assumption that the weight assigned to an observation is inversely proportional to the variance related to residuals. It is considered that the observations that cause greater variability in the residuals are less reliable than those with lower variance in terms of the parameters of the covariates estimated.

Taking into account the hierarchical framework and assessing the direct effects of the distal, intermediate and proximal determinants on the prevalence of asthma, three sets of regression models were performed for each level of determinants, separately; those significant variables $(\mathrm{p} \leq$ $0.10)$ were selected.

In the second stage, and assuming that socioeconomic determinants act through interrelated intermediate and proximal factors, we performed several linear regression models introducing the variables in accordance with the hierarchical framework consecutively. Thus, we fitted the model A, which includes the significant variables of level 1 and 2, and estimated the remaining effect of socioeconomic variables not mediated by the environmental variables as the overall effect of model A.

Finally, and from the model A, we added the significant variables of level 3, which assessed the effect of distal variables not mediated through either environmental or health related variables, as well as the overall effect of model B.

For each model, complete regression diagnoses were performed to corroborate the regression assumptions. The statistical analysis was done using Stata, version 10 (StataCorp LP, College Station, USA).

\section{Results}

The ISSAC III showed an average prevalence of current wheezing among urban Latin American schoolchildren aged 13-14 years of $16.1 \%$, with a wide difference between centers that ranged from $4.6 \%$ to $30.5 \%$. The independent variables also showed large variations between centers (Table 1).

Figure 2 shows the relationship between asthma prevalence and covariates at visual inspection. The correlation coefficient was significant for Gini index ( $r=0.54 ; \mathrm{p}=0.0001)$, HDI $(r=-0.30$; $\mathrm{p}<0.05)$, sewage $(\mathrm{r}=-0.29 ; \mathrm{p}<0.05)$, homicide mortality rate $(\mathrm{r}=0.29 ; \mathrm{p} \leq 0.05)$ and crowding $(\mathrm{r}=$ $-0.23 ; \mathrm{p} \leq 0.10$ ). These variables showed similar behavior in the regression analysis.

The intra-level analysis for distal determinants showed a direct statistical association for Gini index ( $\beta=0.44 ; 95 \% \mathrm{CI}$ : $0.24 ; 0.63$ ) and an inverse one for HDI ( $\beta=-28.6$; 95\%CI: $-60.7 ; 3.44)$. Simultaneous inclusion of both variables in the same model keeps correlations significat and in the same direction, while reduced the strength of the correlation for HDI ( $\beta=-18.8$; 95\%CI: -42.03 ; 4.36) and for the Gini index $(\beta=0.39$; $95 \% \mathrm{CI}$ : 0.22 ; 0.57 ), accounting for $35 \%$ of the variation in the observed asthma prevalence. According to this model, a one point increase in the Gini Index predicted an increase of 0.39 points in the asthma prevalence, whereas a one point increase 
Socioeconomic factors, living conditions and health conditions for 48 Latin American urban centers, 2000-2003.

\begin{tabular}{lcccc}
\hline Variables & Mean & SE & Minimum & Maximum \\
\hline Asthma symptoms prevalence & 16.07 & 5.37 & 4.6 & 30.5 \\
Distal variables & & & & \\
$\quad$ Gini index (\%) & 54.31 & 7.0 & 41.5 & 68.0 \\
$\quad$ Human Development Index & 0.79 & 0.04 & 0.71 & 0.9 \\
Intermediate variables & & & & \\
$\quad$ Households with piped water supply (\%) & 83.3 & 12.9 & 46.8 & 98.6 \\
$\quad$ Households with adequate sanitation (\%) & 85.1 & 15.4 & 44.6 & 99.6 \\
$\quad$ Crowding (average inhabitants per household) & 3.9 & 0.5 & 2.6 & 5.2 \\
Proximate variables & & & & 60.4 \\
$\quad$ Infant mortality rate variation (\%) & 25.9 & 14.5 & -6.4 & 92.0 \\
$\quad$ Homicide rate (per 100,000) * & 25.6 & 24.2 & 1.5 & 27.8 \\
Mean annual temperature $\left({ }^{\circ} \mathrm{C}\right)$ & 21.2 & 5.1 & 5.9 &
\end{tabular}

SE: standard error.

* Four cities excluded due to missing data.

in the HDI would result in a decrease of 0.18 in the asthma prevalence among the studied adolescents (Table 2).

For the intermediate variables, the crude analysis for crowding and sanitation was significant and inversely associated with asthma prevalence while directly associated for water supply. However, in the intra-level multivariate analysis only crowding ( $\beta=-2.80$; 95\%CI: $-5.83 ;-0.24$ ) and sanitation ( $\beta=-0.13$; $95 \% \mathrm{CI}$ : $-0.23 ; 0.02)$ remained in the model. In agreement with this model, a smaller proportion of houses with crowding and adequate sanitation was associated with higher asthma prevalence.

Among the proximal variables, only the homicide mortality rate exhibited a statistical association with asthma prevalence in crude and adjusted analysis ( $\beta=1.57$; 95\%CI: $0.10 ; 3.05$ ) indicating that places with a higher homicide mortality rate also have higher asthma prevalence. In relation to mean annual temperature, it was slightly associated with asthma prevalence in the bivariate analysis ( $\beta=0.27$; 95\%CI: 0.003 ; 0.56 ).

To address the hierarchical approach and to assess the independent contribution of each level of determinants, models A and B were performed. Since we postulated that socioeconomic level may have an effect on asthma prevalence not mediated by the environmental level, we added the intermediate significant variables to the distal significant ones (Gini index and HDI). The direct association of Gini index was attenuated but remained significant $(\beta=0.32 ; 95 \% \mathrm{CI}$ : $0.12 ; 0.51)$, and the influence of HDI increased slightly ( $\beta=-21.0$; 95\%CI: -42.18 ; 0.18 ) when adjusting for environmental variables. Similarly, the effect of crowding was attenuated $(\beta=-2.37$; 95\%CI: -5.07 ; 0.33 ) but sanitation remained outside the model (Model A).

Finally, a model for asthma prevalence was fitted using all significant variables from the reduced regression models of distal, intermediate and proximal determinants. Then significant proximal variables were added to model A to perform model B. After the adjustment for health related variables, HDI $(\beta=-20.54 ; 95 \% \mathrm{CI}$ : $-42.67 ;-1.58)$, and Gini index coefficients $(\beta=$ 0.32; 95\%CI: 0.10 ; 0.54 ) did not change substantially. The strength of association for crowding increased ( $\beta=-2.62$; 95\%CI: $-5.35 ; 0.11$ ), while the homicide mortality rate fell outside the model. As shown in Table 3, this final reduced model accounted for $44.17 \%$ of the variance in the asthma prevalence among adolescents in these Latin American urban centers.

\section{Discussion}

This ecological study explores the role of some relevant social and environmental determinants explaining the variation in asthma prevalence among adolescents from a large sample of Latin American urban centers. Our results showed that socioeconomic and environmental indicators are associated to wheezing in adolescents at the ecological level. Asthma prevalence increased with higher levels of inequality (measured by the 
Figure 2

Scatter plots with smoothing of the prevalence of wheezing in the last 12 months in students aged 13-14 and selected socioeconomic and environmental indicators.

2a) Gini index

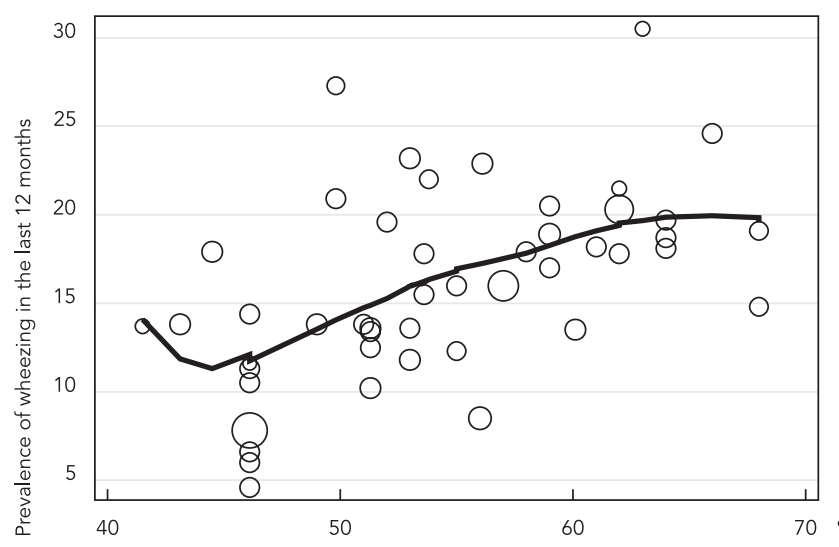

2c) Water supply
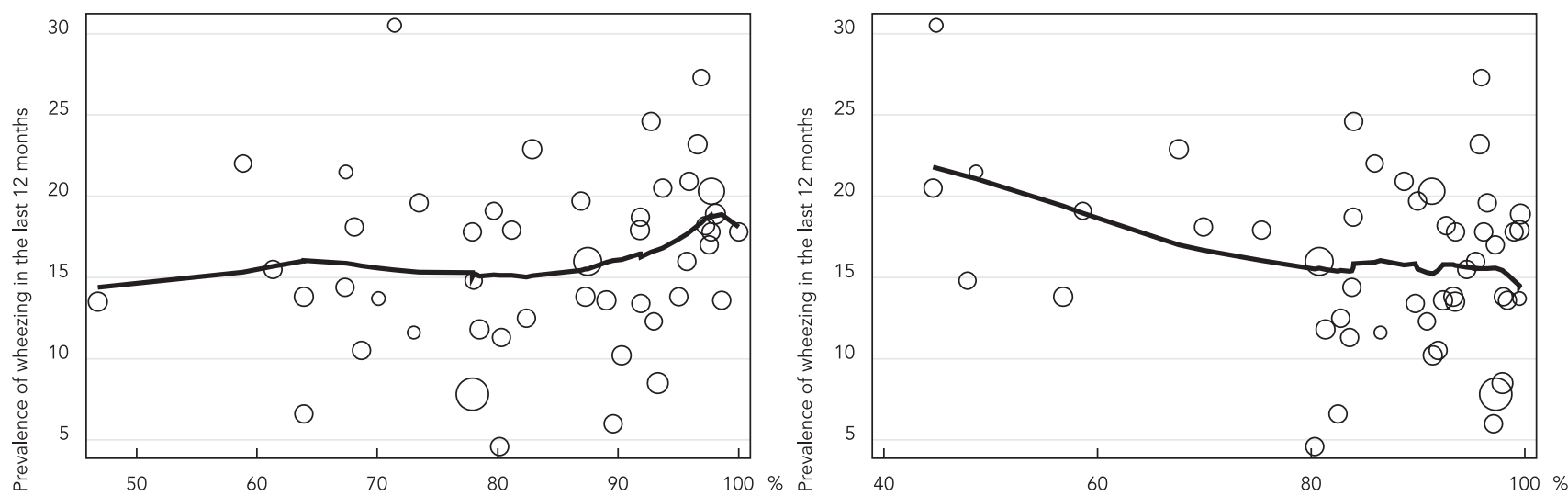

2e) Crowding

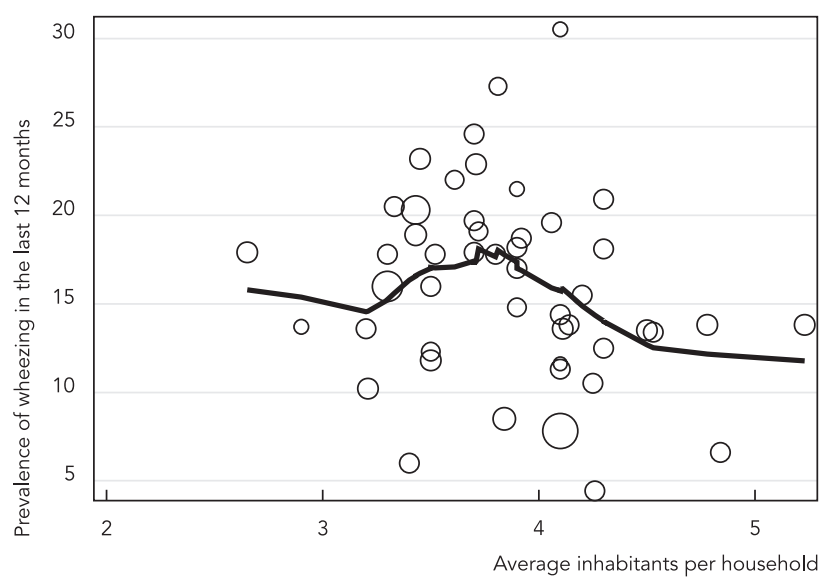

2b) Human Development Index (HDI)

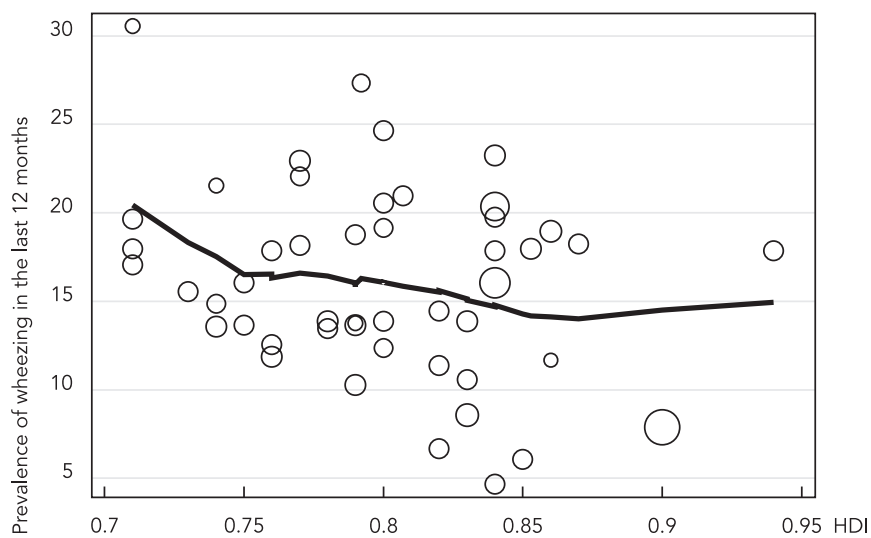

2d) Sanitation

2f) Variation in infant mortality rates

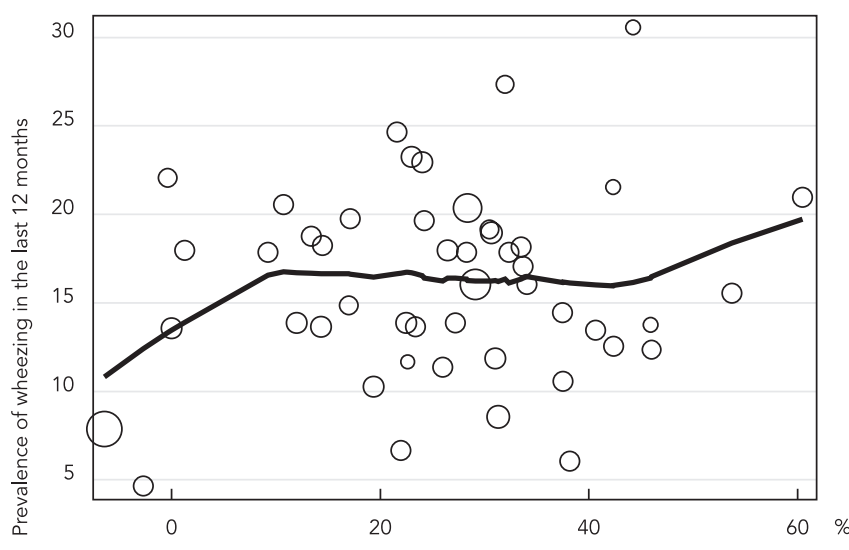


2g) Homicide mortality rate

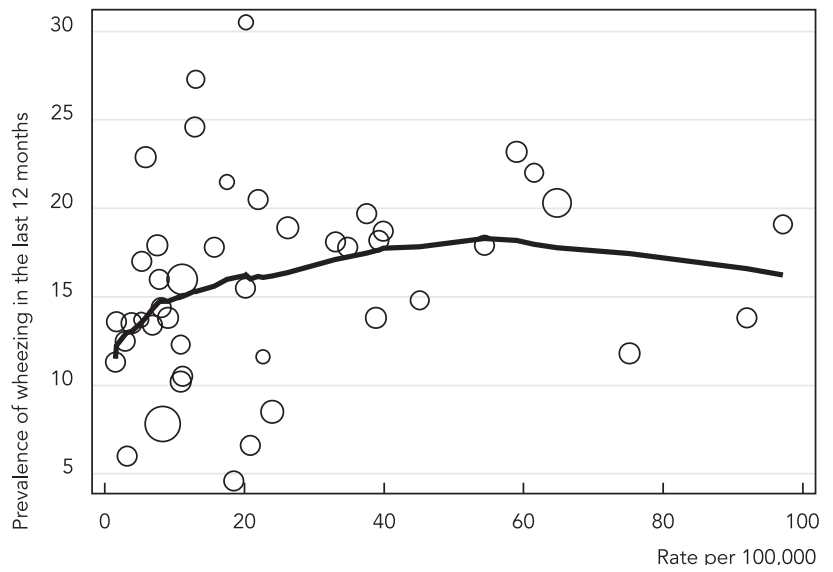

2h) Mean annual temperature

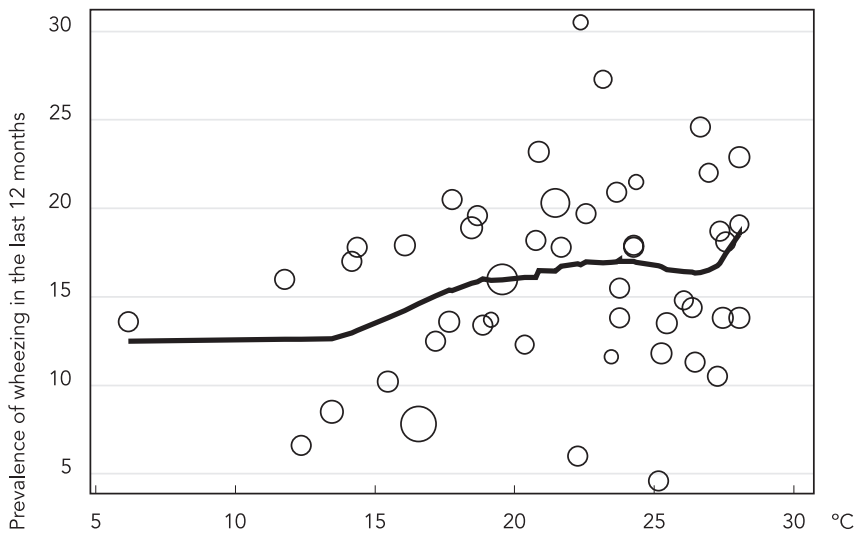

Table 2

Bivariate and multivariate intra-level analysis of determining asthma factors among adolescents aged 13-14 years living in Latin America urban centers, 2000-2003.

\begin{tabular}{|c|c|c|c|c|c|c|}
\hline \multirow[t]{2}{*}{ Variables } & \multicolumn{3}{|c|}{ Bivariate analysis } & \multicolumn{3}{|c|}{ Multivariate analysis (by level) } \\
\hline & $\beta$ (SE) & $95 \% \mathrm{Cl}$ & $\mathrm{R}^{2}(\%)$ & $\beta(\mathrm{SE})$ & $95 \% \mathrm{Cl}$ & $\mathrm{R}^{2}(\%)$ \\
\hline \multicolumn{7}{|l|}{ Level I (distal determinants) } \\
\hline Gini index & $0.44(0.09)$ * & $0.24 ; 0.63$ & 32.3 & $0.39(0.08)$ * & $0.22 ; 0.57$ & 35.24 \\
\hline Human Development Index & $-28.6(15.95) * \star$ & $-60.7 ; 3.44$ & 0.08 & $-18.8(10.9) * \star$ & $-42.03 ; 4.36$ & \\
\hline \multicolumn{7}{|l|}{ Level II (intermediate determinants) } \\
\hline Water supply & $0.09(0.05) * \star$ & $0.01-0.20$ & 8.11 & $0.08(0.05)$ & $-0.03-0.20$ & 22.56 \\
\hline Crowding & $-3.43(1.52) *$ & $-6.50 ;-0.35$ & 10.84 & $-2.80(1.50) * *$ & $-5.83 ;-0.24$ & \\
\hline Sanitation & $-0.09(0.050) * \star$ & $-0.19 ; 0.03$ & 6.80 & $-0.13(0.05) * \star$ & $-0.23 ; 0.02$ & \\
\hline \multicolumn{7}{|l|}{ Level III (proximate determinants) } \\
\hline Infant mortality rate variation & $0.08(0.06)$ & $-0.04 ; 0.20$ & 5.83 & $0.08(0.05)$ & $-0.02 ; 0.19$ & 19.6 \\
\hline Homicide rate & $1.76(0.59)$ * & $0.57 ; 2.95$ & 11.62 & $1.57(0.73)$ * & $0.10 ; 3.05$ & \\
\hline Mean annual temperature & $0.27(0.14) * \star$ & $-0.003 ; 0.56$ & 7.29 & $0.17(0.16)$ & $-0.15 ; 0.50$ & \\
\hline
\end{tabular}

95\% $\mathrm{Cl}$ : $95 \%$ confidence interval; SE: standard error.

* $\mathrm{p}$-value $<0.05$;

** $p$-value $\leq 0.10$

Gini index), lower levels of human development (measured by HDI) and lower levels of household crowding.

While much has been learned about individual risk factors that lie relatively close to asthma at the individual level, fewer studies have explored the structural causes, responsible for the overall increase in the asthma prevalence at the population level. Our findings suggest that some fundamental causes (such as the level of wealth inequalities and the level of human development) constitute main determinants of asthma prevalence among urban Latin Americans adolescents. 
Hierarchical analysis of determining asthma factors grouped by levels among adolescents aged 13-14 years living in Latin America urban centers, $2000-2003$.

\begin{tabular}{|c|c|c|c|c|c|c|}
\hline \multirow[t]{2}{*}{ Variables } & \multicolumn{3}{|c|}{$\begin{array}{l}\text { Model A } \\
\text { (block I-II) }\end{array}$} & \multicolumn{3}{|c|}{$\begin{array}{c}\text { Model B } \\
\text { (block I-II-III) }\end{array}$} \\
\hline & $\beta$ (SE) & $95 \% \mathrm{Cl}$ & $\mathrm{R}^{2}(\%)$ & $\beta$ (SE) & $95 \% \mathrm{Cl}$ & $\mathbf{R}^{2}(\%)$ \\
\hline \multicolumn{7}{|l|}{ Level I (distal determinants) } \\
\hline Gini index & $0.32(0.09)$ * & $0.12 ; 0.51$ & & $0.32(0.11)$ * & $0.10 ; 0.54$ & \\
\hline Human Development Index & $-20.99(10.49) * \star$ & $-42.18 ; 0.18$ & & $-20.54(10.94) * \star$ & $-42.67 ; 1.58$ & \\
\hline \multicolumn{7}{|c|}{ Level II (intermediate determinants) } \\
\hline Crowding & $-2.37(1.33) \star \star$ & $-5.07 ; 0.33$ & & $-2.62(1.35) * \star$ & $-5.35 ; 0.11$ & \\
\hline \multirow[t]{2}{*}{ Sanitation } & $-0.33(0.04)$ & $-0.11 ; 0.05$ & & & & \\
\hline & & & 39.80 & & & \\
\hline \multicolumn{7}{|l|}{ Level III (proximate determinants) } \\
\hline \multirow[t]{2}{*}{ Homicide mortality rate } & & & & $0.53(0.62)$ & $-0.73 ; 1.80$ & \\
\hline & & & & & & 44.17 \\
\hline \multicolumn{7}{|c|}{ 95\% Cl: 95\% confidence interval; SE: standard error. } \\
\hline \multicolumn{7}{|l|}{${ }^{*} p$-value $<0.05$} \\
\hline${ }^{\star *} p$-value $\leq 0.10$ & & & & & & \\
\hline
\end{tabular}

There is much evidence that income inequality is harmful to health; more egalitarian societies usually have a better health status 21 . According to this hypothesis, it is not individual income which is the main determinant of health but rather the degree of income inequality within a society. Inequality may be related to asthma throughout interrelated pathways. It has been hypothesized that the effect of relative deprivation damages social cohesion, with unequal societies being characterized by more violence, hostility and mistrust. Unequal societies promote social environments marked by poor quality social relationships, social stratification and difficult early childhood, that could work as chronic stressors. It is well known that different kinds of stressors could potentially influence health behaviors and affect asthma morbidity 22 , especially in lower income groups which bear a disproportionate burden of unfavorable social circumstances and multiple sources of stress.

Adolescents from low socioeconomic status may be more exposed to stressful situations and events of greater severity. Moreover, they would perceive the same event in a more threatening fashion 11, responding to adverse situations with psychological stress and negative emotions or developing risky health behaviors like smoking, which may affect pulmonary function 23 .

On the other hand, the connection between inequality and health has also been attributed to investment in human capital, where unequal societies tend to spend less in education, health care, service and infrastructure 24. Poor urban environments are characterized by a higher concentration of indoor and outdoor air pollution, reduced availability of green spaces and less access to healthy foods - in addition to psychosocial factors - aspects of urbanization and modern urban life that are associated with asthma 2. This is consistent with our results of an inverse relationship between human development, measured by HDI, and prevalence of wheezing. We can postulate that investment in human capital, in addition to economic capital, may affect the distribution of risk factors for asthma. It is expected that more equitable societies devote resources to creating less hazardous environments, promoting healthy behaviors, and also investing in education and health prevention and promotion. In this way, the investment in human development would determine the extent to which people are able to avoid the risk of asthma morbidity.

According to our results, the effect of socioeconomic determinants is partially produced by environmental variables. Higher household water supply, lower sanitation and crowding were related to asthma prevalence at the intra-level analysis. Despite the apparent contradiction of this finding according to the hygiene hypothesis, improvement in living conditions is related to an increase of atopic asthma. Certainly, Latin America is undergoing an important process of urbanization and development; however it is far from uniform, therefore the extremes of wealth and poverty coexist in the region. Since asthma is not a single entity, and there are different mecha- 
nisms and risk factors for atopic and nonatopic asthma 25 , the overlap of these different immunological profiles in the Latin American context is expected 26 .

Another measure of stress, the homicide mortality rate, was associated to asthma in the bivariate analysis. Relative deprivation is a stronger predictor of the homicide rate, and it was assumed to reflect disruption of community organization, weak social controls and a lack of social cohesion 18. Exposure to community violence is one marker of psychosocial stress, but it is also a marker for neighborhoods with a concentrated disadvantage where people could be exposed to physical or social conditions that contribute to the development of asthma or exacerbate its symptoms and even interfere with its treatment 27 . Various studies identified an association between community violence and asthma prevalence, as well as hospitalizations and emergency visits $27,28,29$.

Our results are in line with other studies showing a correlation between asthma prevalence and indicators of social inequality 14 and national income level ${ }^{30}$. In the latter the authors reported a bimodal distribution of asthma symptoms, higher in high- and low-income countries, and lower in middle-income countries. It is likely that a mix of environmental factors contributes differently according to the country's wealth levels. While some factors could predominate in low income countries, others are more relevant in high income ones. In this last group, where the atopic phenotype predominates, the hygiene hypothesis may have been shown to be more adequate to explain the high prevalence 31 .

Our previous analysis performed in the younger group (6-7 year-olds) evidenced a strong association between Gini index, environmental variables and health related variables, including infant mortality rate and homicide rate and asthma prevalence 15 . In the group of 13-14 year-olds included here, the Gini index effect was shared with the HDI, reflecting the importance of the level of inequality of societies as the level of community wellbeing. In young children, the asthma prevalence was more correlated with proximal factors such as living conditions and health conditions, however, in adolescents the prevalence was predominantly correlated with structural factors. Thus, distal factors may be partial proxies of country socioeconomic level and cultural differences, and can represent a variety of global factors with the potential to have some effect on asthma occurrence, like dietary intake patterns and tobacco smoking prevalence ${ }^{13}$. Also, distal factors may determine the extent to which poor communities concentrate physical and social disadvantages, with the usual impact on the disease occurrence 29 .

Some studies have described the potential role of climate conditions on asthma prevalence and other allergic diseases, showing that extreme temperature and rapid decreases in temperature can increase the risk of asthma attacks 19. Similarly, other studies have shown that higher temperatures were associated with physician's diagnosis of asthma 32 , or with asthma prevalence in adults 33 .

However, we found a weak association between the levels of temperature and wheezing, which may be due to the use of the annual mean temperature, once monthly or daily data were not available for all the participating centers in the study period. Furthermore, it is important to consider other environmental factors linked to global climate change, especially in urban settings. Environmental pollution would affect air quality through several pathways, including traffic-related pollutants 32 , dust and production of allergens 34 . Some of these pollutants could cause respiratory disease or exacerbate asthma symptoms in susceptible children, especially in urban environments. In this way, in developing countries from Latin America, higher pollution levels were correlated to wheezing, allergies, bronchitis and pneumonia 35 .

This study has several strengths, such as the use of a validated measure of asthma symptoms provided by the ISAAC through a standardized protocol, and the addressing of potential determinants of asthma prevalence in a region as large as Latin America, using urban centers as units of analysis. The ecological approach is appropriate to examine the effect of the economic, social, and environmental exposure factors on health, especially if environmental causes of illness are sought 36 . A weighted regression method was used which gave appropriate relative importance to the variables and allowed us to obtain parameters that were more accurate and in the expected direction.

The results should be interpreted with caution, especially because relationships between factors at the ecological level may not be the same as at the individual level, and we cannot adjust for individual confounding factors. However, some of the variables introduced in our analysis are exclusively ecological ones, such as the Gini index and HDI, operating exclusively at the population level. Thus, their effects are not restricted to the poor, but extend to all social strata, and thus are expected to be shared by all members of the society 37 .

An additional limitation is related to the lack of information on air pollution and annual varia- 
tion of temperature for the participating urban centers at the time of the asthma data collection, factors that play a role on the burden of the disease.

Finally, the prevalence of wheezing in the past 12 months is a measure that is very correlated to severe asthma, and it is possible that the pattern of social and environmental determinants observed is more concerned with severe and uncontrolled asthma than with asthma prevalence. The high burden of disease observed may be the result of a set of interrelated adverse social situations, in which the access to diagnosis and preventive care is fundamental to achieving adequate disease management and crisis prevention.

In conclusion, this ecological analysis has explored some social and environmental factors providing evidence of the potential influence of poverty and inequalities on current wheezing among adolescents in a complex social context such as Latin America. In recent decades, the region has been experiencing a rapid process of urbanization and internal migration, reflected in disorganized urban growth leading many people to live in poverty and in stressful urban environ- ments. The growth of disadvantaged neighborhoods coexists with different degrees of urban development compared to the most privileged areas. The transformation of urban spaces is accompanied by changing lifestyles and hence environmental exposures, with a consequent impact on lung development and immune response 38,39. In Latin America, the non-atopic asthma phenotype is dominant but the frequency of atopy is also high and is expected to increase as the living conditions of populations improve. Therefore, the findings from this cross-sectional ecological analysis could reflect the complex dynamic of asthma and allergies in this region of the world 40 .

From a public health perspective, we consider it important to approach the structural determinants of health and contextualize exposure factors which make individuals more vulnerable to develop and aggravate asthma symptoms. Recognizing some of the limitations of ecological studies, we consider it important to explore these relationships in greater depth, incorporating the different phenotypes of asthma, through a multilevel approach.

\section{Resumen}

La prevalencia de asma es alta en áreas urbanas de América Latina, cuyas sociedades exhiben altos niveles de desigualdad y diferente grado de desarrollo. El objetivo de este estudio es examinar la relación entre la prevalencia de síntomas asmáticos en adolescentes de centros urbanos de América Latina y determinantes socioeconómicos y ambientales medidos a nivel ecológico. La prevalencia de síntomas asmáticos se obtuvo del International Study of Asthma and Allergies in Childhood (ISAAC) fase III. Se definió un modelo conceptual jerárquico. Las variables explicativas se organizaron en tres niveles: distal, intermedio, proximal. Se ajustaron modelos de regresión lineal ponderados por el tamaño de la muestra entre la prevalencia de síntomas asmáticos y las variables seleccionadas. La prevalencia de asma fue asociada positivamente con el índice de Gini, Índice de Desarrollo Humano y suministro de agua, e inversamente con hacinamiento y saneamiento ambiental. En conclusión, este estudio proporciona evidencias de la influencia de la pobreza y de la desigualdad social sobre los síntomas asmáticos en adolescentes en un contexto social complejo como el de América Latina.

Asma; Adolescente; Área Urbana 


\section{Contributors}

G. L. Fattore conducted the literature research, data analysis, interpretation of results and writing the article. C. A. T. Santos contributed to the analysis and interpretation of results. M. L. Barreto contributed to the preparation and execution of the project and the interpretation of the results. All authors contributed to the final drafting and revision of the article.

\section{References}

1. Pearce N, Aït-Khaled N, Beasley R, Mallol J, Keil U Mitchell E, et al. Worldwide trends in the prevalence of asthma symptoms: phase III of the International Study of Asthma and Allergies in Childhood (ISAAC). Thorax 2007; 62:758-66.

2. Cooper PJ, Rodrigues LC, Cruz AA, Barreto ML. Asthma in Latin America: a public health challenge and research opportunity. Allergy 2009; 64:5-17.

3. Gold DR, Wright R. Population disparities in asthma. Annu Rev Public Health 2005; 26:89-113.

4. Weinmayr G, Weiland SK, Björkstén B, Brunekreef B, Büchele G, Cookson WO, et al. Atopic sensitization and the international variation of asthma symptom prevalence in children. Am J Respir Crit Care Med 2007; 176:565-74.

5. Cunha SS, Barreto ML, Fiaccone RL, Cooper PJ, Alcantara-Neves NM, Simões SM, et al. Asthma cases in childhood attributed to atopy in tropical area in Brazil. Rev Panam Salud Pública 2010; 28:405-11.
6. Burr ML, Anderson HR, Harkins LS, Kaur B, Strachan DP, Warner JO. Respiratory symptoms and home environment in children: a national survey. Thorax 1999; 54:27-32.

7. Rodríguez MA, Winkleby MA, Ahn D, Sundquist J, Kraemer HC. Identification of population subgroups of children and adolescents with high asthma prevalence: findings from the Third National Health and Nutrition Examination Survey. Arch Pediatr Adolesc Med 2002; 156:269-75.

8. Garcia E, Aristizabal G, Vasquez C, Rodríguez-Martínez CE, Sarmiento OL, Satizabal CL. Prevalence of and factors associated with current asthma symptoms in school children aged 6-7 and 13-14 year old in Bogota, Colombia. Pediatr Allergy Immunol 2008; 19:307-14. 
9. Squillace SP, Sporik RB, Rakes G, Couture N, Lawrence A, Merriam S, et al. Sensitization to dust mites as a dominant risk factor for asthma among adolescents living in central Virginia. Multiple regression analysis of a population-based study. Am J Respir Crit Care Med 1997; 156:1760-4.

10. Poyser MA, Nelson H, Ehrlich RI, Bateman ED, Parnell S, Puterman A, et al. Socioeconomic deprivation and asthma prevalence and severity in young adolescents. Eur Respir J 2002; 19:892-8.

11. Chen E, Fisher EB, Bacharier LB, Strunl R. Socioeconomic status, stress, and immune markers in adolescents with asthma. Psychosom Med 2003; 65:984-92.

12. Lai CK, Beasley R, Crane J, Foliaki S, Shah J, Weiland $\mathrm{S}$, et al. Global variation in the prevalence and severity of asthma symptoms: phase three of the International Study of Asthma and Allergies in Childhood (ISAAC). Thorax 2009; 64:476-83.

13. Asher MI, Stewart AW, Mallol J, Montefort S, Lai CKW, Aït-Khaled N, et al. Which population level environmental factors are associated with asthma, rhinoconjunctivitis and eczema? Review of the ecological analyses of ISAAC Phase One. Resp Res 2010; 11:8.

14. Cunha SS, Pujades-Rodriguez M, Barreto ML, Genser B, Rodrigues LC. Ecological study of socioeconomic indicators and prevalence of asthma in schoolchildren in urban Brazil. BMC Public Health 2007; 7:205.

15. Fattore GL, Santos CA, Barreto ML. Social determinants of childhood asthma symptoms: an ecological study in urban Latin America. J Commun Health 2014; 39:355-62.

16. Anderson HR, Gupta R, Kapetanakis V, Asher MI, Clayton T, Robertson CF, et al. International correlations between indicators of prevalence, hospital admissions and mortality for asthma in children. Int J Epidemiol 2008; 37:573-82.

17. Hoffman K, Centeno MA. The lopsided continent: inequality in Latin America. Annu Rev Sociol 2003; 29:363-90.

18. Wilkinson RG, Kawachi I, Kennedy BP. Mortality, the social environment, crime and violence. Sociol Health Ill 1998; 20:578-97.

19. Hashimoto M, Fukuda T, Shimizu T, Watanabe S, Watanuki S, Eto Y, et al. Influence of climate factors on emergency visits for childhood asthma attack. Pediatr Int 2004; 46:48-52.

20. Xu Z, Huang C, Su H, Turner LR, Qiao Z, Tong S. Diurnal temperature range and childhood asthma: a time-series study. Environ Health 2013; 12:12.

21. Wilkinson RG, Pickett KE. Income inequality and population health: a review and explanation of the evidence. Soc Sci Med 2006; 62:1768-84.

22. Wilkinson RG, Pickett KE. Income inequality and social dysfunction. Annu Rev Sociol 2009; 35:493-511.

23. Jackson B, Kubzansky LD, Cohen S, Weiss S, Wright RJ. A matter of life and breath: childhood socioeconomic status is related to young adult pulmonary function in the CARDIA study. Int J Epidemiol 2004; 33:271-8.

24. Kaplan GA, Pamuk ER, Lynch JW, Cohen RD, Balfour JL. Inequality in income and mortality in the United States: analysis of mortality and potential pathways. BMJ 1996; 312:999-1003.
25. Strina A, Barreto ML, Cooper PJ, Rodrigues LC. Risk factors for non-atopic asthma/wheeze in children and adolescents: a systematic review. Emerg Themes Epidemiol 2014; 11:5.

26. Pitrez PM, Stein RT. Asthma in Latin America: the dawn of a new epidemic. Curr Opin Allergy Clin 2008; 8:378-83.

27. Wright RJ, Mitchell H, Visness CM, Cohen S, Stout J, Evans R, et al. Community violence and asthma morbidity: The Inner-City Asthma Study. Am J Public Health 2004; 94:625-32.

28. Apter AJ, Garcia LA, Boyd RC, Wang X, Bogen DK, Ten Have T. Exposure to community violence is associated with asthma hospitalizations and emergency department visits. J Allergy Clin Immunol 2010; 126:552-7.

29. Alves GDC, Santos DN, Feitosa CA, Barreto ML. Community violence and childhood asthma prevalence in peripheral neighborhoods in Salvador, Bahia State, Brazil. Cad Saúde Pública 2012; 28:86-94.

30. Sembajwe G, Cifuentes M, Tak SW, Kriebel D, Gore R, Punnett L. National income, self-reported wheezing and asthma diagnosis from the World Health Survey. Eur Respir J 2010; 35:279-86.

31. Brooks C, Pearce N, Douwes J. The hygiene hypothesis in allergy and asthma: an update. Curr Opin Allergy Clin 2013; 13:70-7.

32. Guo YL, Lin YC, Sung FC, Huang SL, Ko YC, Lai JS, et al. Climate, traffic-related air pollutants, and asthma prevalence in middle-school children in Taiwan. Environ Health Persp 1999; 107:1001-6.

33. Hales S, Lewis S, Slater T, Crane J, Pearce N. Prevalence of adult asthma symptoms in relation to climate in New Zealand. Environ Health Persp 1998; 106:607-10.

34. Beggs PJ, Bambrick HJ. Is the global rise of asthma an early impact of anthropogenic climate change? Environ Health Persp 2005; 113:915-9.

35. Bella ML, Davis DL, Gouveia N, Borja-Aburto VH, Cifuentes LA. The avoidable health effects of air pollution in three Latin American cities: Santiago, São Paulo, and Mexico City. Environ Res 2006; 100:431-40.

36. Marmot MG. Improvement of social environment to improve health. Lancet 1998; 351:57-60.

37. Wilkinson RG, Pickett KE. Income inequality and socioeconomic gradients in mortality. Am J Public Health 2008; 98:699-704.

38. Figueiredo CA, Amorim LD, Alcantara-Neves NM, Matos SM, Cooper PJ, Rodrigues LC, et al. Environmental conditions, immunologic phenotypes, atopy, and asthma: new evidence of how the hygiene hypothesis operates in Latin America. J Allergy Clin Immun 2013; 131:1064-8.

39. Figueiredo CA, Alcântara-Neves NM, Veiga R, Amorim LD, Dattoli V, Mendonça LR, et al. Spontaneous cytokine production in children according to biological characteristics and environmental exposures. Environ Health Persp 2009; 117:845-9.

40. Cooper PJ, Rodrigues LC, Barreto ML. Influence of poverty and infection on asthma in Latin America. Curr Opin Allergy Clin 2012; 12:171-8.

Submitted on $01 / \mathrm{Jul} / 2014$

Final version resubmitted on 26/Apr/2015

Approved on 04/May/2015 